\title{
Laboreal
}

Volume $16 \mathrm{~N}^{\circ} 2$ | 2020

Programa de Pesquisa do Curso da Ação

\section{Toxicologia e ergonomia}

Toxicología y ergonomía

Toxicologie et ergonomie

Toxicology and ergonomics

\section{Robert Villatte}

\section{(2) OpenEdition}

\section{Journals}

\section{Edição electrónica}

URL: http://journals.openedition.org/laboreal/16413

DOI: 10.4000/laboreal.16413

ISSN: 1646-5237

\section{Editora}

Universidade do Porto

\section{Refêrencia eletrónica}

Robert Villatte, «Toxicologia e ergonomia », Laboreal [Online], Volume 16 №2 | 2020, posto online no dia 01 dezembro 2020, consultado o 14 dezembro 2020. URL : http://journals.openedition.org/ laboreal/16413; DOI : https://doi.org/10.4000/laboreal.16413

Este documento foi criado de forma automática no dia 14 dezembro 2020.

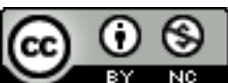

Laboreal está licenciado com uma Licença Creative Commons - Atribuição-NãoComercial 4.0 Internacional. 


\section{Toxicologia e ergonomia}

Toxicología y ergonomía

Toxicologie et ergonomie

Toxicology and ergonomics

Robert Villatte

\section{REFERÊNCIA}

Texto original: Villatte, R. (1985). Toxicologie et ergonomie. In Bernard Cassou, Dominique Huez, Marie-Laurence Mousel, Catherine Spitzer, \& Annie TouranchetHebrard (1985). Les risques du travail. Pour ne pas perdre sa vie à la gagner (pp. 301-303). Paris: La Découverte.

\section{NOTA DO EDITOR}

Tradução: João Viana Jorge - joaojorg@gmail.com

Determinar valores limite para a exposição a produtos tóxicos baseia-se geralmente no seguinte raciocínio: exposto a um produto, presente em média em determinada concentração, um operador médio apresentará perturbações funcionais características. Considerando uma margem de segurança pode obter-se um valor limite para a concentração desse produto na atmosfera.

2 Do mesmo modo, o raciocínio que conduz ao estabelecimento de tabelas de doenças ditas profissionais articula-se em torno das mesmas noções: um operador médio de um certo sector de atividade exposto a determinada nocividade e apresentando os sintomas especificamente ligados a essa nocividade, poderá ser indemnizado a título de doença profissional.

3 Estes raciocínios são criticáveis. São, é verdade, oriundos de um processo social no qual entram considerações económicas, jurídicas ou outras fortemente dependentes das 
relações sociais da época mas essa não é a crítica fundamental que quereríamos aqui desenvolver.

4 Esses raciocínios apoiam-se de facto numa conceção do homem ultrapassada face aos conhecimentos científicos recentes e sobre um conceito de exposição teórico claramente alheio à exposição real em situação de trabalho.

5 Há já uma vintena de anos, a cronobiologia pondo em evidência muito numerosos ritmos biológicos, levou a rever certas hipóteses que pretendiam que a resistência de um indivíduo a um produto tóxico fosse constante. A noção de ritmo biológico é de facto antiga e bem conhecida de todos - como por exemplo a alternância da vigília e do sono no decurso da jornada de 24 horas. Mas o que se demonstrou foi que as funções e os órgãos corporais, como as células que os compõem, estão também submetidos a ritmos biológicos. Uma célula não pode fazer tudo ao mesmo tempo, regula o ritmo das suas atividades biológicas. As consequências de tais descobertas são consideráveis. Assim, um medicamento não tem os mesmos efeitos sobre o organismo (benéficos ou nocivos) conforme o momento em que é administrado. O que é válido para os medicamentos também o é para os tóxicos industriais.

6 Do mesmo modo, considerar que existe um «homem médio» com reações médias é contraditório com os conhecimentos adquiridos sobre a dispersão dos parâmetros fisiológicos numa população de indivíduos e a sua evolução no decurso da vida. A noção de homem adulto, indiferenciada entre o fim da adolescência e a terceira idade é, portanto, fortemente contestável tanto do ponto de vista científico como do ponto de vista das consequências económico-sociais que esta visão implica (modelo taylorista do homem no trabalho).

\section{Uma conceção teórica desmentida pelos factos}

7 Uma observação de uma meia hora, numa oficina de produção, num laboratório, num hospital leva rapidamente à conclusão que a exposição a (produtos) tóxicos no decurso da atividade de trabalho não corresponde à visão simplista que prevaleceu até ao presente.

8 É extremamente raro encontrar ambientes de trabalho onde reine um único produto, identificado, estabilizado. Mais frequentes são os ambientes em que se misturam substâncias mais ou menos puras, mais ou menos degradadas. É o caso dos laboratórios de química mas também da maior parte das oficinas da química, das de tratamento de superfícies, das da indústria farmacêutica.

9 As características dos produtos variam em função de numerosos factores; podem assim apresentar-se em diversas fases, em diversas condições (temperatura), e sofrer degradações que transformam e modificam a sua toxicidade (por exemplo a gordura que se deteriora num molde quente).

10 A ininterrupta introdução de novos produtos químicos de síntese, a polivalência de utensílios e oficinas que os fabricam ou os transformam, as condições do mercado (produtos diversificados, ...) também explicam a variabilidade da exposição.

11 Essas mesmas oficinas atravessadas por correntes de ar, cujas características atmosféricas flutuam, acentuam o carácter fictício da noção de concentração estável, de um produto estável, numa atmosfera estável. 
12 A cinética dos gases numa oficina depende, portanto, de um grande número de parâmetros (correntes de ar, fontes de calor, atividades, temperatura no exterior, ...). Torna-se difícil de modelar, de antecipar.

13 A démarche clássica esquece-se também de considerar as atividades que os operadores levam de facto a cabo nestes ambientes tóxicos. Ora a exposição (em termos de quantidade de produto inalado, por exemplo) será radicalmente diferente dependendo dessas atividades. Assim, um determinado operário na produção irá estar exposto a fracos níveis de concentração do produto durante a sua jornada de trabalho. Em contrapartida o operário da manutenção, intervindo na mesma oficina, num órgão perto da fonte de onde emana o produto, inalará durante um tempo mais curto concentrações muito mais elevadas. Não há nenhuma razão para considerar a priori que os efeitos de uma mesma quantidade de produto inalado destas duas maneiras serão equivalentes.

Para um dado ambiente atmosférico a inalação poderá ser dez vezes mais abundante (em litros por minuto, por exemplo) para um operador que cumpra um trabalho físico do que para um outro que preencha papéis sentado à secretária.

Por outro lado, um ar poluído já não fornece tanto oxigénio por litro de ar como o ar (dito) «normal»; é, pois, necessário respirar mais depressa. Do mesmo modo o aumento da temperatura do local de trabalho vai requerer uma frequência de ventilação pulmonar mais elevada. Com a idade a capacidade respiratória diminui (aos sessenta anos é metade da dos trinta). Por isso para um mesmo trabalho este tem de ser compensado por uma frequência ventilatória mais elevada.

Inversamente não é impossível que um ambiente atmosférico considerado «não tóxico», mas poluído agrave consideravelmente a carga de trabalho nomeadamente se se trata de um solvente como o tricloroetileno que lentifica as faculdades percetivas e mentais.

17 Falta enfim ter em conta os problemas de interação. Raros são com efeito os produtos em que a ação conjunta diminua a atividade de cada um. O mais frequente é que não se trate de uma simples justaposição ou de uma adição dos seus efeitos, mas de uma multiplicação dos efeitos de um pelos efeitos do outro. Fala-se então em sinergia. Neste domínio os conhecimentos são limitados. Os protocolos das pesquisas de toxicidade têm sobretudo tendência para analisar situações simplificadas em que não se colocam problemas de interação. Sabe-se, todavia, que a exposição combinada aos produtos a seguir referidos implica efeitos sinérgicos: esforço + tricloroetileno; nitroglicerina + TNT; asma + mistura de poeiras; calor + solvente; solvente + sabão; sílica + amianto; mistura de poeiras; mistura de solventes; zinco + cádmio; etc.

\section{Para uma prática ergotoxicológica}

Uma abordagem ergotoxicológica implica que, a partir de agora, se utilizem as normas mais como pontos de referência que como garantias de ausência de perigo. Implica que a toxicidade dos produtos deveria ser avaliada a partir da entrada em linha de conta das características dos trabalhadores que a eles estão expostos: idade, sexo, antiguidade no posto de trabalho, antecedentes médicos, e, evidentemente tipo de atividade de trabalho. Os conhecimentos dos mecanismos toxicológicos tal como os efeitos da 
interação dos diversos produtos em presença são indispensáveis. De facto, um ror de conhecimentos estão em falta e requerem pesquisas.

19 Esta abordagem deve permitir, por outro lado, encontrar soluções técnicas adaptadas aos problemas de poluição que se colocam numa oficina. Afasta com efeito, de uma penada só, qualquer dispositivo que sobrecarregue a (normal) carga de trabalho. Seria aliás rejeitada de facto pelo operador.

20 Abre a via a uma (outra) abordagem não apenas em termos de toxicidade dos produtos, mas também em termos de incómodo, de irritação ... que pesam na carga de trabalho e estão na origem de modificações de estratégias operatórias (estratégias de evitamento de fumos, de projeções, por exemplo).

21 Esta abordagem permite também debater as prioridades das ações de prevenção: é assim no quadro de um programa anual de prevenção de riscos profissionais e de melhoria das condições de trabalho. Oferece com efeito a possibilidade de hierarquizar as urgências de intervenção face às diversas atividades levadas a cabo.

Por fim, esta abordagem permite, na perspetiva de uma mobilidade da mão-de-obra entre diversos postos (de trabalho), portanto em situações de exposição diversificadas, pesquisar as modificações, tanto ao nível dos produtos como ao nível das atividades, que facilitam a adaptação dos postos a uma população o mais extensa possível.

\section{BIBLIOGRAFIA}

Cowles, F. Effet sur l'homme d'expositions professionnelles combinées. Note documentaire 1268-100-80, INRS.

Delvolve, N. (1984). Ergonomie et toxicologie. Le Travail humain, 47. 